\title{
Propuesta clasificatoria de un grupo de representaciones de nzahki entre los otomíes de San Pablito, Pahuatlán, Puebla*
}

\author{
Alberto Diez Barroso Repizo \\ y Alfonso Margarito García Téllez
}

Parte del imaginario del mundo natural de los grupos nahuas y otomíes de la Sierra Norte de Puebla puede representarse con figuras de papel denominadas nzahki, en lengua otomí, que simbolizan la energía vital en los humanos, los animales, las plantas y las entidades del inframundo, similar al tonalli de la cultura nahua. Estas representaciones forman parte de la medicina tradicional indígena y de la cosmovisión. Hay diversas entidades en el universo del nzahki, con propiedades que nos permiten clasificarlas. Es posible encontrar correspondencias entre algunos elementos de un mismo grupo, como las entidades asociadas con el diablo, la noche y el señor de Moctezuma. El médico tradicional, hacedor de lluvia llamado curandero, interactúa con las entidades del mundo natural a través de sus representaciones en papel.

PALABRAS CLAVE: otomí, nzahki, ñhañhú, Pahuatlán, medicina tradicional, Sierra Norte de Puebla, amate, amatl, ò diablo, infierno, noche

\section{A Classification Proposal for a Group of Representations of Otomí Nzahki, from San Pablito, Pahuatlán, Puebla \\ Some characters of the imaginary natural world of Otomí and Nahua peoples from the Sierra Norte de Puebla can be represented by paper figures call nzahki in Otomí language. They symbolize the vital energy of humans, animals, plants, and entities of the underworld, similar to Nahua tonalli.These representations involve the indigenous medical practices, and its view of the world. There are several entities with attributes that allow its classification. It's possible to find correspondences within elements of a group, as the associations with the devil, the night, ant the Lord of Moctezuma. The traditional doctor, the rain maker named curandero, interacts with the entities of the natural world through the paper representations.}

KEYWORDS: otomí, nzahki, ñhañhú, Pahuatlán, traditional medicine, Sierra Norte de Puebla, amate, amatl, devil, hell, night

Alberto Diez Barroso Repizo: Escuela Nacional de Antropología e Historia, Distrito Federal, México piedrasal@hotmail.com

Alfonso Margarito GarcíaTéllez: curandero de San Pablito, Pahuatlán, Puebla, México

Desacatos, núm. 39, mayo-agosto 2012, pp. 15-28

Recepción: 20 de mayo de 2009 / Aceptación: 15 de abril de 2011

* Agradezco a Alfonso Margarito García Téllez por su confianza y disposición para compartir sus conocimientos, sin los que no hubiera sido posible la realización de este artículo. A Carlos Guadalupe Heiras Rodríguez y a Antonio Romero Huerta, por sus acertados comentarios y observaciones. 
Para Rebeca

\section{INTRODUCCIÓN}

$\mathrm{D}$ entro de la cosmovisión otomí o ñhañhú, el nzahki es el espíritu, la fuerza viva de los seres naturales o sobrenaturales, la energía corporal o extracorporal de cada ser (García, comunicación personal, 2005; Galinier, 1990; Dow, 1974; Díaz, 1988). Las representaciones más comunes se observan bajo la forma de un muñeco de papel de China o amate. Pueden aludir a plantas, animales, fenómenos naturales - como el rayo, el granizo, el arco iris- e incluso a elementos introducidos durante la evangelización en el siglo XVI —que inicialmente no tuvieron un parámetro de significación con elementos conocidos en la idiosincrasia indígena, como el diablo, los judíos y el Presidente del Infierno, por lo que rápidamente adquirieron un sentido diferente del que la cultura occidental les ha asignado- - . Las entidades se han clasificado en benéficas y patógenas desde un punto de vista dualista en el que subyace la dicotomía del bien y el mal (Galinier, 1990).

Nuestro objetivo se centra en explicar la interacción de un subgrupo de entidades patógenas que, al ser analizado, permite aproximarnos al conocimiento de la cosmovisión ${ }^{1}$ ñhañhú y a los procesos de aculturación por los que ha atravesado este grupo étnico. El tema de este estudio surgió gracias al análisis formal de un "libro de curación"2 (García,

\footnotetext{
${ }^{1}$ Entendida como la forma en que un grupo social determinado interpreta el mundo y los fenómenos inherentes a la persona. Incluye las manifestaciones oníricas, psicológicas y cognitivas. Esta interpretación, aceptada por consenso en el grupo social, llega a ser un elemento indispensable de la identidad del grupo. Según Montemayor, sólo podemos aproximarnos de manera objetiva a la cosmovisión evitando esquemas prejuiciosos de la cultura occidental, como el etnocentrismo, el cual pone en un segundo plano al hacedor del hecho social que pretendemos estudiar: el "informante" indígena (Montemayor, 2000: 95-106).

${ }^{2}$ Libro elaborado artesanalmente por el mismo autor.
}

s/f) tradicional indígena, elaborado por un badi o curandero muy conocido en la comunidad de San Pablito, municipio de Pahuatlán, en el estado de Puebla.

Alfonso aprendió el arte de curar por una tradición ancestral: su padre y su abuelo también fueron curanderos. A partir de la década de los setenta del siglo $\mathrm{xx}$, comenzó a registrar sus conocimientos en libros hechos de papel amate con figuras que representan entidades. Cada libro explica un ritual. Nos mostró uno llamado de curación y otro para petición de lluvia. En nuestro estudio de caso trataremos el Libro de curación, que menciona los pasos a seguir para contrarrestar el "ataque" causado por una "enfermedad mala" a una persona. Haremos un análisis general de las entidades representadas y trataremos en lo particular un subconjunto de nzahki que forma un grupo de entidades consideradas patógenas que se relacionan entre ellas.

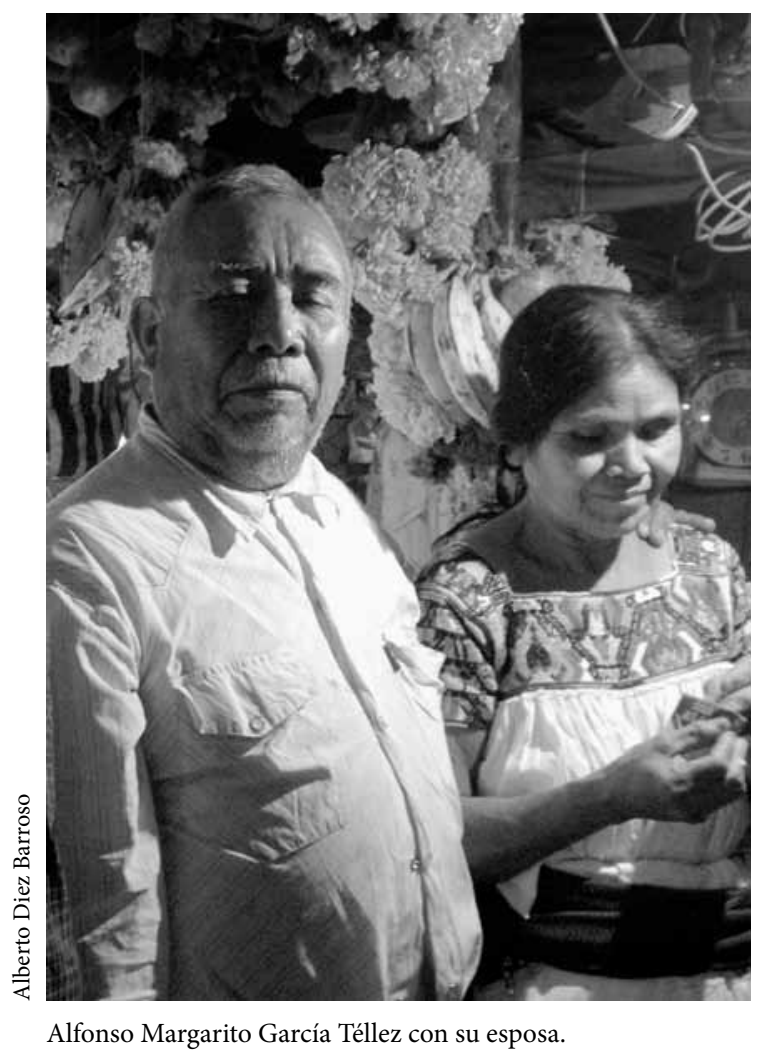




\section{EL MARCO GEOGRÁFICO}

San Pablito se localiza en el municipio de Pahuatlán, en el estado de Puebla, en el área geográfica de la Sierra Norte de Puebla, hacia el límite sur de la Huasteca (véase figura 1). Con una altitud de 1180 metros sobre el nivel del mar, San Pablito presenta un clima templado-húmedo con lluvias todo el año y con una temperatura media anual de entre los 12 y los $18{ }^{\circ} \mathrm{C}$, lo que favorece el desarrollo del bosque mesófilo de montaña asociado a vegetación arbustiva. En las riberas de los ríos puede encontrarse vegetación de tipo selva alta perennifolia (INEGI, 1987). Con una población aproximada de 2851 habitantes (INEGI, 2005), de los cuales la mayoría son hablantes de ñhañhú, la principal actividad socioeconómica de la comunidad es la producción de papel obtenido de la corteza de una especie arbórea del género ficus, higuerilla, conocida localmente

Figura 1. Localización de San Pablito, Pahuatlán, y de la Sierra Norte de Puebla

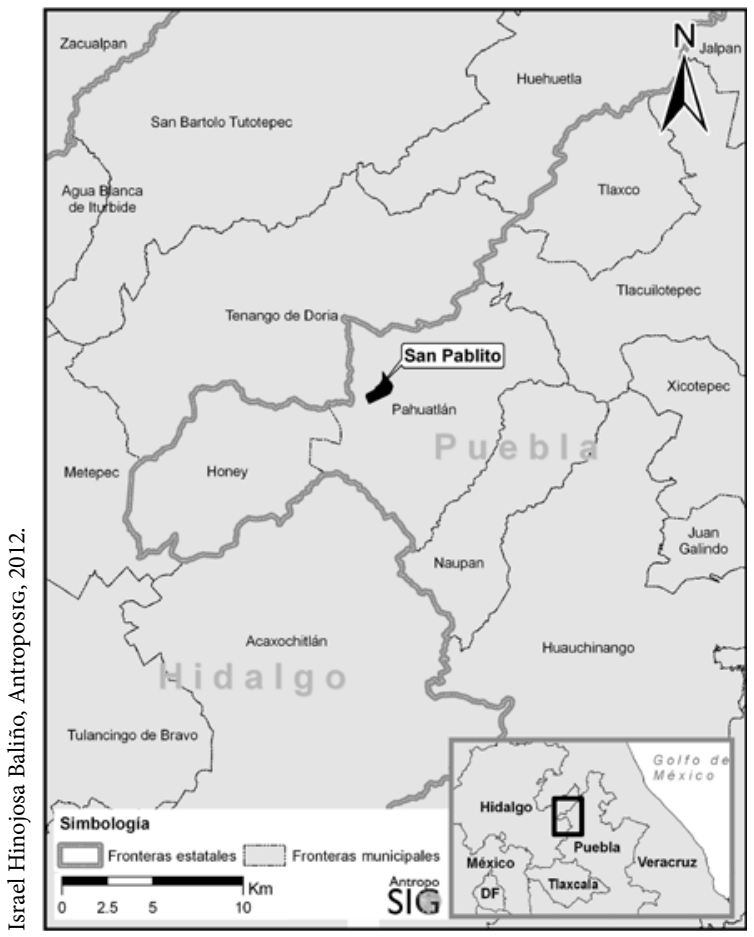

como jonote, a cuya corteza se le llama amate, del náhuatl amatl, que se traduce como "papel". Aunque el proceso de manufactura del papel amate ha sufrido un cambio considerable en las últimas dos décadas con la introducción de nuevas técnicas para blanquear la corteza - como el uso de sosa cáustica一, todavía pueden observarse elementos de tradición indígena, como la utilización de desfibradores y machacadores de material lítico.

\section{ELTRABAJO DE CAMPO}

En 2005 conocí a Alfonso García Téllez, uno de los curanderos tradicionales más nombrado por los antropólogos que llegan a San Pablito. Entonces nuestros objetivos de investigación eran otros, pero obtuvimos datos concernientes a las ceremonias propiciatorias de lluvia y al ritual que se efectúa en caso de alguna enfermedad, conocida como "ataque" dentro de la terapéutica tradicional indígena. Replanteamos los objetivos en lo general hacia una aproximación a la cosmovisión ñhañhú y en lo particular a un grupo de entidades patógenas representadas en el Libro de curación.

Una vez elegido el objeto de estudio, el trabajo se dividió en tres fases fundamentales: la recopilación bibliográfica y de archivo, el trabajo etnográfico y el análisis y la selección de datos. Durante el proceso de investigación se estructuró una estrategia para cada fase, algunas de las cuales se llevaron a cabo de manera simultánea. La metodología a seguir para el trabajo etnográfico se construyó a medida que surgían datos bibliográficos, a los que se sumaron los primeros acercamientos analíticos de los nzahki y de la estructura del discurso ritual narrado en el Libro de curación. Posteriormente, se efectuó el análisis del Libro y su relación con los nzahki representados, y se clasificaron en conjuntos a partir de la secuencia narrativa original del texto. Tomamos como punto de partida la clasificación original del badi, pero detectamos dentro de esta clasificación, que podemos llamar "nativa", un subgrupo que actúa de manera 
Figura 2. Libro de curación elaborado en papel amate, volumen procedente de San Pablito, Pahuatlán, Puebla

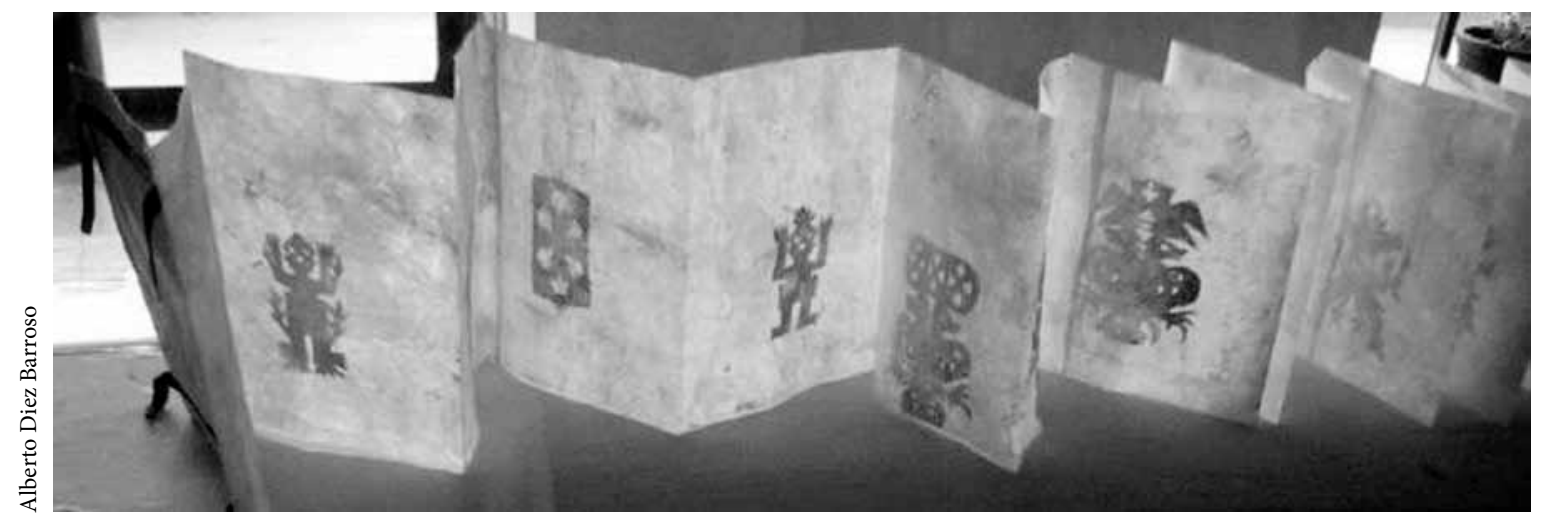

independiente al gran conjunto de entidades patógenas y que interactúa estrechamente entre sus elementos para causar el mal a la persona y también para retirarlo. La contribución de quien esto suscribe a las tipologías de nzahki más conocidas (Dow, 1974; Sandstrom y Sandstrom, 1986; Díaz, 1988; Galinier, 1990, 2009; Oliver, 1997; Báez-Jorge y Gómez, 2000) es la presencia y análisis de este subgrupo.

Respecto de lo que pudimos conocer sobre el $b a$ $d i$, sabemos que adquirió su "don" de curar gracias a los conocimientos heredados de su padre, que a su vez los heredó de su abuelo. La obtención del "don” fue por herencia genética, pero cabe señalar que esta modalidad no es una constante, pues muchas veces es por medio de los sueños, de manifestaciones de las deidades a través de ataques epilépticos, patologías psicológicas ${ }^{3}$ o bien a partir de la influencia de otros integrantes de la comunidad (Romero y Heiras, 2010, comunicación personal).

\section{EL LIBRO DE CURACIÓN. ESTRUCTURA NARRATIVAY CLASIFICACIONES}

El Libro de curación fue elaborado sobre un soporte de papel amate de $19 \times 14 \mathrm{~cm}$ en forma de biombo,

\footnotetext{
${ }^{3}$ Gruzinski (1988) menciona cierto grado de esquizofrenia detectada a un curandero totonaco del siglo xvir al analizar detalladamente su proceso inquisitorial.
}

compuesto por 30 hojas incluyendo la portada (véase figura 2). Originalmente, la manufactura de este tipo de libros tenía como objetivo conservar los conocimientos para las futuras generaciones (García, 2007, comunicación personal). En la actualidad constituyen un objeto de intercambio comercial apreciado por el turismo antropológico. En la primera hoja se lee a tinta:

Ceremonia religiosa contra la brujería. Para la gente que crea bie[n] la costumbre de antigua, esta enfermedad se llama ataque. Por ejemplo: como una persona que encuentra una malo en el campo, para curar esta enfermedad se tiene que llamar un curandero (García, s/f).

Luego se describe paso a paso el ritual para contrarrestar el "ataque", todo escrito en tinta de bolígrafo convencional, alternando con figuras de papel amate recortado. El soporte es de papel amate en color blan$\mathrm{co}$, mientras que las figuras son de papel amate oscuro. El libro no tiene fecha de elaboración, pero otro similar del mismo autor llamado Tratamiento de una ofrenda para pedir la lluvia en San Pablito Pahua-tlán, Pue., tiene fecha del 10 de agosto de 1978.

Las primeras ocho páginas describen la ceremonia de petición de ayuda al enfermo, dirigida a un primer conjunto de entidades benéficas compuesto por los dioses del monte, el agua, el árbol, el Viento Bueno y la Reina de la Tierra. No aparece la representación 
de su $n z a h k i$, en su lugar fueron colocados los espíritus de hombres y mujeres buenos y malos, así como la "cama de ataque", que sirve de soporte para la ofrenda al momento de realizar el ritual. Denominamos "Conjunto I" a este grupo que contiene a los $n z a h k i$ de seres terrenales y objetos rituales materiales, como la "cama de ataque" (véase figura 3). De la página 9 a la 18 podemos identificar una serie de entidades patógenas. Éstas ocupan el "Conjunto II", conformado por el Presidente del Infierno, Señor de Diablo, el Señor de Judío y el Señor de Noche (véase figura 4), el Señor de Relámpago, el Señor de Trueno, El Señor de Moctezuma, el Arco Iris, la Sirena Mala, el Señor de Nagual, el Trompa de Toro y la Señora Trompa de Caballo (véase figura 5). Dentro de este gran conjunto de entidades patógenas encontramos un subconjunto de entidades que interactúan entre sí, presentes en el ritual de curación contra un "ataque" o enfermedad: Subconjunto IIA, y será el que analizaremos. Se diferencia del resto del Conjunto II porque las entidades que lo constituyen dependen unas de otras para "trabajar" y están estrechamente ligadas por y para lo mismo.

Finalmente, a partir de la página 19 aparece otro conjunto compuesto por el Señor del Monte, el Águila de Cuatro Cabezas, el Pajarito del Monte, el Pajarito de Mono, el Pajarito de Estrella, la Madre Tierra, la Cama del Monte, el Dios del Árbol, el Señor de Antigua y culmina con el nacimiento de Cristo. Este conjunto, al parecer, reúne en su mayoría entidades terrenales, algunas de ellas relacionadas

Figura 3. Conjunto I

A) "Cama de ataque"; B) Hombre bueno; C) Mujer buena; D) Hombre malo;

E) Mujer mala

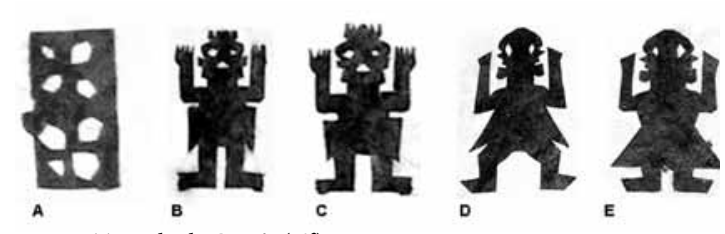

con los mitos de creación, como el Pajarito del Monte y el Águila de Cuatro Cabezas. Se catalogó como "Conjunto III" (véase figura 6).

\section{ASPECTOS FORMALES DE LAS ENTIDADES SOBRENATURALES}

Al observar la muestra de los tres conjuntos que aparecen en el Libro de curación sobresalen a primera vista las peculiaridades formales de cada entidad. En principio, y en relación con la postura del cuerpo, todas las entidades sobrenaturales se encuentran de pie con el cuerpo de frente y en $97 \%$ de los casos con los brazos arriba, en tanto que el resto los tiene hacia abajo, como el Señor de Nagual y la Sirena Mala. ${ }^{4}$ Hay dos tipos de semblantes en la muestra total: las figuras con el rostro al frente y otras con dos rostros viendo de perfil que convergen en la parte posterior de la cabeza. Todas las figuras con un solo rostro son entidades benéficas y conjugan seres sobrenaturales y espíritus de vegetales comestibles, mientras que $90 \%$ de las identificadas como patógenas presentan el rostro bifrontal. La excepción es el conjunto de aves, que se representan también con doble rostro, no se relacionan con aspectos patógenos y por lo general se vinculan con los mitos de la creación (García, 2006, comunicación personal).

La totalidad de entidades patógenas exhibe los pies calzados, en tanto que las entidades benignas están descalzas. Don Alfonso explica que como "Jesucristo andaba descalzo", por ende los seres buenos así andan. En lo que concierne a la postura de los brazos de las entidades catalogadas, $99 \%$ de la muestra los presenta hacia arriba, con independencia de la categoría benéfica o patógena. El uso del machete es exclusivo de las entidades patógenas, aunque no todas lo portan: unas lo presentan hacia arriba - el

\footnotetext{
${ }^{4}$ Cotejamos esta pequeña muestra con otras, entre ellas las del acervo del Museo Nacional de Antropología e Historia de la ciudad de México, publicada por Oliver (1997), con el fin de ampliar el rango de comparación.
} 
Figura 4. Conjunto II, Subconjunto II-A

A) Presidente del Infierno; B) Señor de Judío; C) Señor de Diablo; D) Señor de Noche

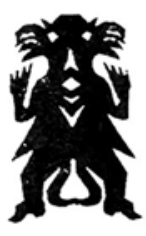

A

Fuente: Tomado de García (s/f).

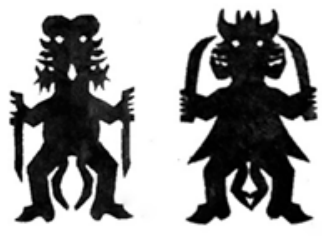

c

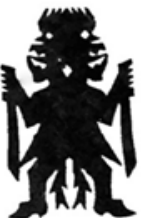

Señor de Diablo y el Trompa de Toro- y otras hacia abajo - el Señor de Judío, el Señor de Noche, el Señor de Moctezuma y el Trompa de Caballo-.

\section{LOS “MALOS ESPÍRITUS", LA ASIGNACIÓN DE UN SIGNIFICADO A LAS NUEVAS IDEOLOGÍAS}

4 La característica bifrontal de las imágenes fue uno de los aspectos más importantes durante el análisis. $\mathrm{Al}$ ser asociada con la información proporcionada por el badi, nos permitió elaborar la tipología o clasificación por conjuntos. El fenómeno dual en la imagen puede transcribir plásticamente un fenómeno ideológico reflejado en la lengua ñhañhú. La imagen de la representación del nzahki de "espíritus malignos" transmite el siguiente difrasismo: la palabra y'ohmi -que transcribe "hipócrita o falso" (Rodríguez, s/f)—, que etimológicamente se compone de yoho, "dos", y hmi, "rostro": "dos rostros", induce la idea de la falsedad como sinónimo de maldad. Dentro de la idiosincrasia ñhañhú, los "espíritus malos" son las almas de individuos que murieron de manera violenta, accidentalmente o sin bautizar (Dow, 1974: 100). Conforme a la clasificación que proponemos basada en el bifrontismo de las representaciones de nzahki, el “espíritu de mestizo" también entraría en este conjunto. Generalmente se representa con barba, sombrero, zapatos y un gran pene (véase figura 7). Este aspecto caracteriza las relaciones sociales entre los ñhañhú y los forasteros en la actualidad. Los últimos suscitan desconfianza en la comunidad indígena como resultado de cientos de años de explotación colonial, situación que no cambió luego de la Independencia, y mucho menos con la Revolución.

No es nuestro objetivo describir las características de todo el corpus de "espíritus malignos" mencionados con anterioridad, pero una vez que analizamos las entidades y su interacción nos detendremos a analizar el Subconjunto II-A, formado por elementos estrechamente ligados: el Presidente del Infierno, el Señor de Judío, el Señor de Diablo y el Señor de Noche (véase figura 4). Los tres primeros provienen de conceptos netamente occidentales, excepto el Señor de Noche, que a primera vista guardaría profundas raíces prehispánicas, aunque el concepto que le atribuyen los ñhañhú alude claramente a una resignificación, como veremos más adelante.

\section{Presidente del Infierno}

Presidente ra košti ra nitũ, en ñhañhú, es clasificado como una fuerza patógena (Galinier, 1990: 177). En la tradición oral de San Pablito, el Presidente del Infierno es quien ordena a todos los judíos y permite que las entidades negativas salgan a esparcir las enfermedades y los males del mundo. Actúa como ordenando, dirigiéndolos (véase figura 8):

\footnotetext{
el Presidente del Infierno es el orquestador de todos los diablos: a la hora que hace la limpia es quien recibe todo la envidia. Los diablos también son como un policía, vamos a traerlos y lo que está molestando vamos a traerlos. Él es Lucifer, el diablo es otro, Lucifer es el Presidente, es el mismo. Es uno de los jueces de esos diablos (García, 2008, comunicación personal).
}

Al observar la clasificación de estas entidades negativas encontramos una gama de jerarquías de los seres demoniacos en el imaginario ñhañhú. Es probable que tengan su origen en la evangelización 
Figura 5. Conjunto II

A) Señor de Relámpago; B) Señor de Trueno; C) Señor de Moctezuma; D) Arco Iris; E) Sirena Mala;

F) Señor de Nagual; G) Trompa de Toro; H) Trompa de Caballo

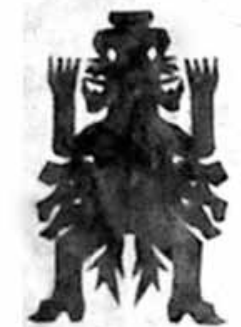

A

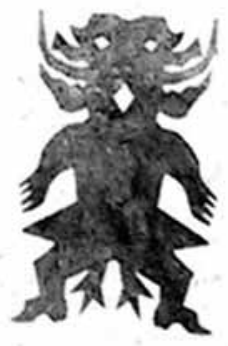

E

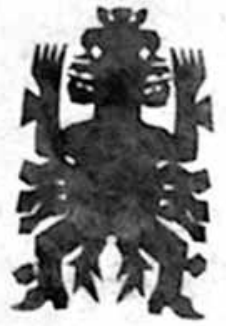

B

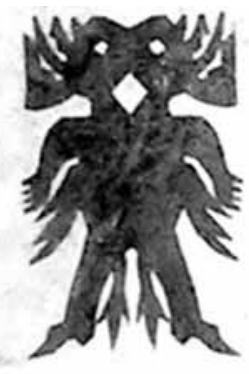

$\mathbf{F}$

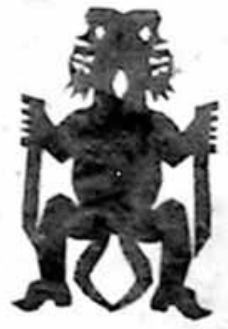

C

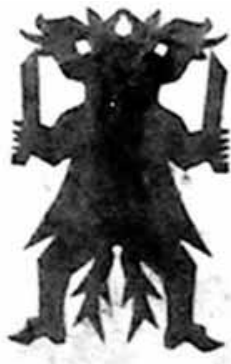

G

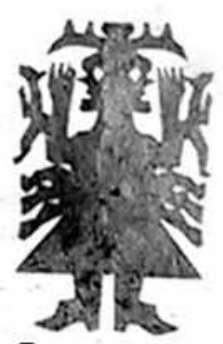

D

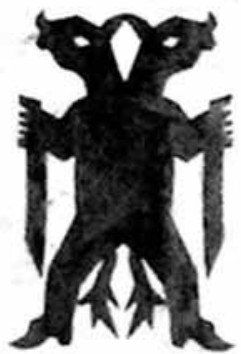

H

Fuente: Tomado de García (s/f).

novohispana, cuyo bagaje reside principalmente en los estudios de Santo Tomás de Aquino y en el célebre tratado inquisitorial del libro Malleus Maleficarum, escrito en 1448, donde se menciona en mayor medida la gama de entes diabólicos que forma parte de la cultura occidental. Lucifer no guarda relación aparente como Presidente del Infierno, más bien se le refiere como un ángel portador de luz, mientras que los Presidentes del Infierno son varios y cada uno dirige sus propias legiones de demonios (Kramer y Sprenger, 2004; Garibay, 2005). Sin embargo, en San Pablito las características de este personaje revelan que se resignificó como el elemento regidor de los "malos aires" causantes de las enfermedades, de tal forma que es la entidad que autoriza la ejecución del mal materializado en la enfermedad. Como entidad de alta jerarquía está a cargo de varios entes patógenos o, de acuerdo con el concepto judeocristiano, al mando de una legión de demonios. Al efectuar la limpia la influencia negativa se le devuelve primeramente a él, según lo explicó el badi.

\section{El Señor de Judío}

Las características del Señor de Judío son descritas de la siguiente manera (véase figura 9):

El Señor de Judío lleva un cuchillo porque quiere sangre. Adonde hay pleito, el Señor de Judío le da el cuchillo a la persona que le gusta pelear, porque quiere sangre (García, s/f).

En el rito de curación, el nzahki de judío es "bautizado" con aguardiente. Deben ser 14 nzahki de judío rociados con esta bebida al momento del ritual y a cada uno se le asigna un nombre. Parte de su 
Figura 6. Conjunto III

A) Señor del Monte; B) Águila de Cuatro Cabezas; C) Águila de Dos Cabezas; D) Pajarito de Mono; E) Pajarito de Estrella; F) Madre Tierra; G) Dios de Árbol; H) Señor de Antigua

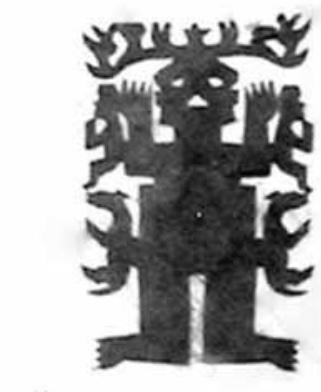

A

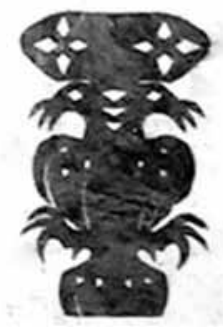

22

E
Fuente: Tomado de García (s/f).

naturaleza negativa se desprende de la violencia que despierta la embriaguez y su reclamo de sangre es colmado con el sacrificio de una gallina negra. Cuatro velas de sebo son colocadas dentro de la casa del enfermo con el fin de que los judíos se alumbren para salir de la casa (García, s/f).

La imagen del judío parece vinculada del todo a las ideas evangelizadoras del siglo xvI, sobre todo a las que hacen alusión a la Pasión de Cristo, representadas de manera didáctica por los frailes en las obras de teatro y explicadas al indígena desde la idiosincrasia occidental. El mensaje que generó este personaje en el imaginario indígena se relacionó de inmediato con los "espíritus malignos", principalmente con el diablo, puesto que, según las palabras del badi, "el Señor de Judío es lo que había mucho antes, antes de Cristo, el día que se ganó el Cristo, ganó Dios, porque Dios es el Cristo" (García, 2008, comunicación personal). Entre los totonacos del siglo

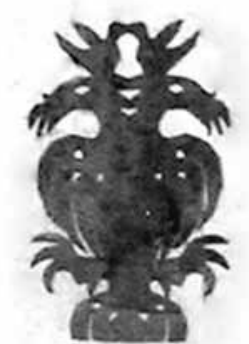

C

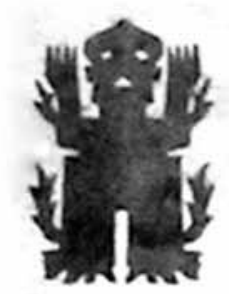

G

XVII también se documentó la presencia de los judíos como entidades maléficas que acompañan a Judas para esparcir enfermedades y muertes:

el judío era una criatura sobrenatural a la que colocaban en el mismo plano que a los apóstoles [...] el judío era el emisario de la ira del Dios todopoderoso, el instrumento del poder exterminador (Gruzinski, 1988: 102-103).

\section{El Señor de Diablo}

Una entidad ligada estrechamente al Señor de Judío es el Señor de Diablo. La descripción desde la idiosincrasia ñhañhú es (véase figura 10):

El Señor de Diablo lleva un machete grande porque quiere carne y adonde hay pleito también le da el 
Figura 7. Nzahki de mestizo

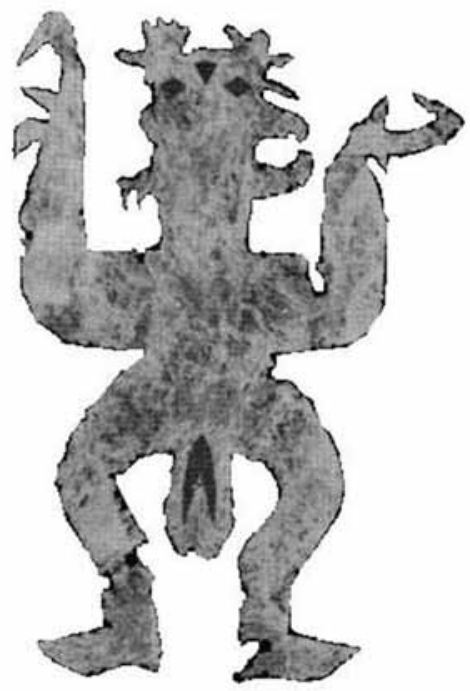

Fuente: Tomado de Oliver (1997).

machete a la persona que le gusta pelear para que le [dé] su sangre y carne entre estas dos persona[s]. El Señor de Judío y el Señor de Diablo siempre van por los caminos o por las cantinas para encontrar su comida (García, s/f).

Zithũ, el Diablo o Señor del Mundo, es una figura ambivalente por naturaleza, incluso sexualmente presenta ambos sexos. No es de extrañar que se represente de manera bifrontal y que forme parte imprescindible de ciertos rituales. Galinier (1990: 295-298) registró entre los otomíes de Piedra Grande, Veracruz, un ritual en el que las plegarias y ofrendas se dedican al diablo pidiéndole que se retire. Las ofrendas consisten en flores, velas, aguardiente, cigarros y cerveza. El diablo es otra entidad que también se sometió al proceso de resignificación indígena. Los evangelizadores enfrentaron el problema de la ausencia de un símbolo o personaje de la cosmovisión indígena que pudiera asociarse con esta entidad (Aguirre Beltrán, 1963). De allí que algunos ejemplos encontrados en los catecismos indígenas del
Figura 8. El Presidente del Infierno

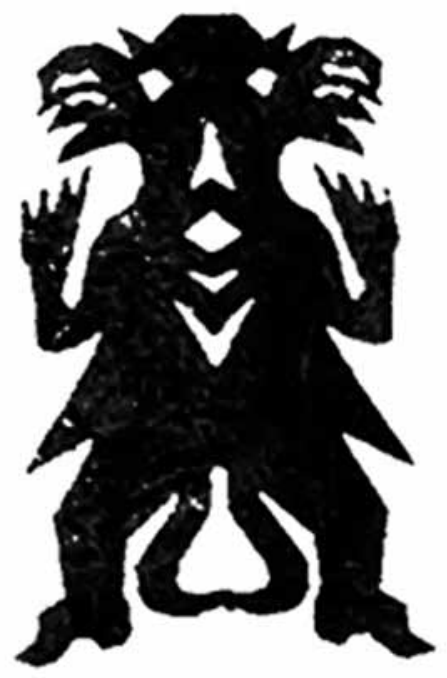

Fuente: Tomado de García (s/f).

siglo xvi aludan a ella como tlacatecolotl, "hombre tecolote", y ahmocualli, "el no bueno" (Galarza, 1992: 137), figura de gran importancia entre los nahuas de Chicontepec (Báez-Jorge y Gómez, 2000: 79-93). En la mentalidad ñhañhú el diablo posee características sui generis que no se encuentran en la ideología cristiana. Por ejemplo:

el diablo también escucha, no es terco, como Dios. Amamos Dios porque escucha, por eso pedimos que ya no vaya a volver a pegarlo, porque vamos a entregar nuestra ofrenda de sangre. Por ejemplo, un borrachito gritaba, molestaba mucho, dale un peso, dale cinco, ahora vete a la chingada, tómate esto. Así es el diablo. Por eso en la limpia hay que saber cómo puede llamarlo (García, 2008, comunicación personal).

En este caso, la sangre del sacrificio de la gallina es para aplacar al "espíritu maligno" y se intercambia por la recuperación del enfermo. Es una especie de don que pretende apaciguarlo y contentarlo temporalmente para que se aleje, al mismo tiempo que es 
Figura 9. El Señor de Judío

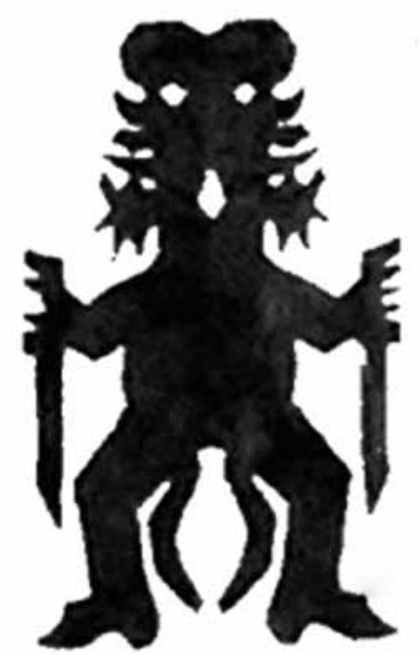

Fuente: Tomado de García (s/f).

un intercambio. Como vimos, la presencia del diablo entre los ñhañhú se ahuyenta ofrendándole y pidiéndole directamente a él. Lo contrario que en la costumbre católica de pedir a algún santo o al mismo Dios su protección o intercesión. Entre los nahuas de Chicontepec, Veracruz, Tlacatecolotl o el Diablo es una entidad dual que presenta aspectos negativos y positivos, masculinos y femeninos, diurnos y nocturnos. También está presente durante las ofrendas y rituales de petición de lluvia. Se le pide que no interfiera en la comunicación con las deidades de la lluvia (Báez-Jorge y Gómez, 2000).

\section{El Señor de Noche}

Esta deidad, la noche misma, es quien guarda las puertas del infierno con el Presidente del Infierno. Su función es permitir a las fuerzas del mal actuar en un tiempo determinado (véase figura 11):

El Señor de Noche dice: yo estoy de dependiente en la puerta del infierno y yo sé la hora que pueden salir a todos los judíos. Les dejo salir desde las 11 de la
Figura 10. El Señor de Diablo

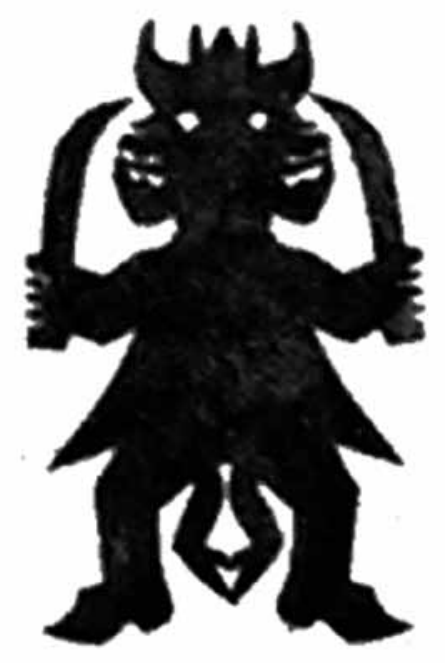

Fuente: Tomado de García (s/f).

noche que es la hora que andan aquí en el mundo, hasta la una de la mañana. Son dos horas que pueden andar aquí en el mundo (García, s/f).

El badi relata que sólo entre las horas cercanas a la media noche es cuando las entidades malignas operan. De hecho, las limpias llamadas “fuertes", encaminadas a retirar alguna brujería, deben ser realizadas durante esas horas, pues si no es así las entidades no están presentes. En ese tipo de terapéutica se efectúa la ofrenda de sangre en la que se sacrifica una gallina negra a las entidades negativas. Contrario a lo que pudiera pensarse, el Señor de Noche no guarda relación aparente con las antiguas deidades mesoamericanas, como Yohualli Ehecatl, "viento de la noche", advocación de Tezcatlipoca. En nuestro estudio de caso es evidente que la entidad se relaciona únicamente con el tiempo, con las horas en las que los espíritus o malos aires se encuentran en el cosmos, y por consiguiente con los horarios propicios para la terapéutica. Entre los nahuas de Huazalingo, Hidalgo, Yohualli Ehecatl aparece durante los cambios de estación para hacer daño, pues es cuando más se enferman las personas (Romero, 2010, comunicación personal). 


\section{EL DISCURSO RITUAL}

Las entidades sobrenaturales que tratamos anteriormente son elementos imprescindibles dentro de la terapéutica ñhañhú. Su esencia cobra vida al momento del ritual encaminado a devolver la salud a un enfermo que ha sido objeto de un "ataque", el cual es una enfermedad causada por un mal aire, generalmente, propiciado por algún individuo que guarda envidia. Algunas veces puede suceder de manera espontánea: recibir un susto estando en el monte y perder el alma. Según el badi, existen dos tipos de enfermedades: las provocadas por la maldad - en las que intervienen las entidades patógenas- y las enviadas por Dios - son curables, por lo general, con herbolaria-. Las enfermedades propiciadas por malos aires deben atenderse con un curandero. Para saber cuál es la causa de la enfermedad, "el curandero le va [a] preguntar al Dios del Monte de la enfermedad que tiene esta persona" (García, $\mathrm{s} / \mathrm{f})$. El texto del libro nos indica someramente que antes de aplicar la terapéutica es preciso llevarle una ofrenda al Dios del Monte para preguntarle por el tipo de enfermedad que padece la persona. Sólo si ésta ha sido víctima de una brujería será tratada mediante el "ritual de curación de antigua" (García, s/f). A partir de esto se coloca la ofrenda de limpia en la casa del enfermo. Una serie de elementos forman parte indisoluble de los dones:

se van a usar 24 cama[s] de papel amate, 24 espíritus malo de papel amate que son los que fracasaron por pistola, machete o puñalada, 24 espíritu bueno de papel amate que son los que murieron por calentura, vómito o diarrea y 14 judíos que también son malos (García, s/f).

Dentro de la casa del enfermo se tienden 12 "camas" de papel amate en forma de cuadro. La "cama" alude a un objeto ritual que sirve como soporte para colocar la ofrenda: es un objeto rectangular de aproximadamente $60 \mathrm{~cm}$ de largo (véase figura 3A), aunque puede variar según el curandero o el tipo de
Figura 11. El Señor de Noche

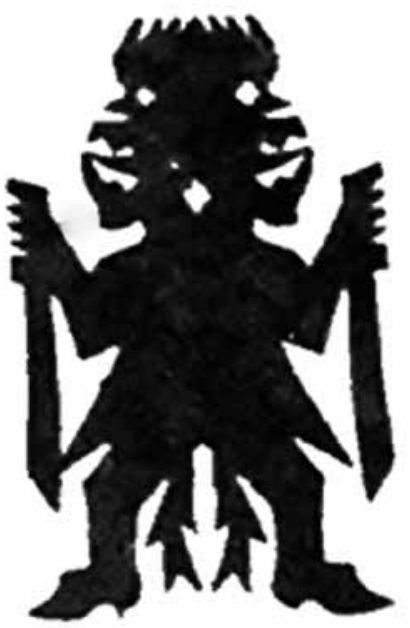

Fuente: Tomado de García (s/f)

ritual (García, 2008, comunicación personal). Los nzahki son colocados sobre la cama, se les rocían gotas de aguardiente y se encienden cigarros a los judíos. Otros elementos están presentes en el ritual: el sacrificio de sangre de una gallina y los rezos que el badi pronuncia en lengua ñhañhú. Éste es el momento culminante en que los nzahki de judíos son bautizados con sangre y aguardiente. Se les ofrecen velas de sebo "para que se alumbren y salgan de la casa". Las velas nos indican la hora propicia en la que el ritual se realiza, pues tienen la función de alumbrar el camino de los judíos, momento que alude intrínsecamente al Señor de Noche. Posteriormente, el badi elabora una silla a partir de un objeto ritual llamado tlapex. La silla como elemento del rito no es para que el badi se siente sobre ella, es para colocar las ofrendas y las figuras de papel previo al bautizo de éstas:

Se hace un tlapex[que] que en forma de una silla, lo hace el curandero, en cada esquina de la tlapexque se coloca una cera de sebo, 12 cama de papel amate, siete judíos de papel de China, se hecha cuatro gotas de aguardientes, por que así se bautiza los judíos (García, s/f). 
Esto se conoce como ceremonia de barrida. Intervienen la música y el canto efectuado por el badi. A partir de que las figuras de papel se rocían con el aguardiente han quedado "bautizadas", entonces se considera que poseen $n z a h k i$, pues antes sólo eran figuras de papel. El proceso ritual del "bautizo" marca la diferencia entre una representación que guarda toda la esencia y fortaleza de una entidad determina$\mathrm{da}$ - provista de nzahki-y las figuras que se comercializan en el mercado. Desafortunadamente, es muy difícil registrar los rezos y cantos del badi en ñhañhú durante la ceremonia, ya que es de carácter privado (Lupo, 1995) y es difícil que se permita la participación de alguien ajeno a la familia del enfermo, con mayor razón si se trata de alguien externo a la comunidad.

Al final de la ceremonia el badi recoge todos los elementos que intervinieron en el ritual y los arroja a una barranca. Durante la travesía de la casa del enfermo a la barranca los músicos acompañan al badi entonando canciones. Luego de esta curación intercio determinado por el badi irá a dejar una ofrenda al Señor del Monte, a los Dioses del Árbol, al agua, al Viento Bueno y a la Reina de la Tierra. Así se cierra el ciclo ritual en el que intervinieron algunas de las entidades representadas en los conjuntos y subconjuntos I, II-A y III de nuestra clasificación. De manera cíclica se inició y culminó el rito con las entidades benéficas. La interacción del subsistema II-A opera tanto al interior de éste como al exterior, al encontrarse enmedio del ciclo en el que las entidades benéficas abren y culminan, según lo expresado en el discurso ritual: se encontraron presentes al principio cuando se les pregunta sobre la causa de la enfermedad y al final cuando el enfermo les agradece.

\section{COMENTARIOS FINALES}

Las entidades que forman el subsistema del Conjunto II-A son elementos exógenos introducidos

por los evangelizadores. Conceptualmente tienen un significado profundo dentro de la mentalidad occidental, pero en la cosmovisión indígena remiten al proceso histórico de evangelización y aculturación que vivieron los otomíes durante el contacto en el siglo XVI, puesto que su presencia sólo puede explicarse al verlas reproducidas durante el carnaval o en las representaciones de la Pasión de Cristo. El ritual ejecutado para cada caso expuesto hace referencia a la relación directa del badi con la entidad patógena. Contrario a lo que se observa en la religión católica, en la que se le reza a las entidades benéficas para que actúen contra los elementos negativos, aquí no hay intermediarios, como los santos, la Virgen o Cristo. Entre los ñhañhú, el badi es el intermediario directo entre la persona común y las entidades sobrenaturales, sean benéficas o patógenas, fenómeno que también se advierte entre algunos grupos nahuas colindantes con la Sierra Norte, como en Chicontepec, Veracruz, donde el huehuetlacatl o ritualista anciano invoca a una entidad sobrenatural ambivalente llamada Tlacatecolotl y a los tlasolehecameh o "malos aires", representados todos en papel ceremonial, con el fin de que no perturben durante el ritual (Báez-Jorge y Gómez, 2000).

En lo concerniente a la característica bifrontal de los entes patógenos, es probable que esté asociada a algunos préstamos ideológico-lingüísticos entre el otomí y el náhuatl, o bien a paralelismos culturales. Ambas lenguas, aunque distantes, comparten algunos vocablos con estructura gramatical y semántica similares, ya que los nahuas adquirieron varios elementos de los otomíes cuando los primeros se asentaron en el Altiplano Central (Ecker, 1990, citado por Bartholomew, 2000: 189-204). Un posible ejemplo es la traducción de "falso o hipócrita", que en ñhañhú se transcribe y'ohmi, que literalmente significa "dos rostros" (Rodríguez, s/f), y del vocablo en náhuatl omeyollo, que transcribe "dos corazones" y cuyo campo semántico es igual que en ñhañhú "falso, hipócrita o embustero" (Simeón, 2004: 356). Como vemos en este concepto, 
las transcripciones náhuatl y ñhañhú para el individuo falso, hipócrita o mentiroso forman parte de una noción moral registrada desde el siglo Xvi por fray Bernardino de Sahagún en los huehuetlahtolli, "palabra de los viejos" (Sahagún, 2000), cuando se refiere a las características del hombre integral y maduro. Las palabras in ixtli in yollotl, "el rostro, el corazón", se yuxtaponen para formar el difrasismo de la personalidad integral del hombre (León Portilla, 2003: 349-355).

Lo observado en el lenguaje se explica como parte de la aculturación entre los grupos étnicos que durante siglos han coexistido en la Sierra Norte de Puebla. Algunos rituales nahuas y ñhañhú comparten similitudes, como la representación de las entidades sobrenaturales en papel entre los nahuas de Chicontepec (Báez-Jorge y Gómez, 2000) y los de Ixhuatlán de Madero (Sandstrom y Sandstrom, 1986; Heiras, 2007), ambos al noreste de Veracruz, por citar sólo algunos. Otro fenómeno propio del proceso de aculturación que vivieron las comunidades serranas es la resignificación de los personajes que intervienen dentro del discurso evangelizador:

la información circulaba, que la aculturación sembraba sus imágenes y sus espantapájaros sin que por eso los indios los absorbieran pasivamente. El objeto era examinado, retocado, desvirtuado de su sentido original [...] era purgado de su dimensión histórica para sólo conservar el poder que fascinaba (Gruzinski, 1988: 103).

La aculturación primero entre los mismos grupos indígenas y posteriormente con los europeos pudo ocurrir intercambiando elementos y reinterpretándolos (Aguirre Beltrán, 1957: 140). Cada etnia formó sus conceptos particulares dentro de un proceso cultural complejo considerando la interrelación de los diversos grupos étnicos que comparten el entorno (López Austin, 2001).

\section{Bibliografía}

Aguirre Beltrán, Gonzalo, 1957, El proceso de aculturación y el cambio sociocultural en México, Universidad $\mathrm{Na}$ cional Autónoma de México, México.

- 1963, Medicina y magia: el proceso de aculturación en la estructura colonial, Secretaría de Educación Pública, Instituto Nacional Indigenista (Serie Antropología Social, núm. 1), México.

Báez-Jorge, Félix y Arturo Gómez Martínez, 2000, “Los equilibrios del cielo y la tierra. Cosmovisión de los nahuas de Chicontepec", en Desacatos. Revista de Antropología Social, núm. 5, Centro de Investigaciones y Estudios Superiores en Antropología Social, núm. 5, pp. 79-94.

Bartholomew, Doris, 2000, "Intercambio lingüístico entre otomí y náhuatl”, en Estudios de Cultura Otopame, vol. 2, Instituto de Investigaciones Antropológicas, Universidad Nacional Autónoma de México, pp. 189-204.

Díaz Mercado, Areli, 1988, "Sistema de creencias mágicoreligioso de los otomíes de San Pablito, Pahuatlán", en La Palabra y el Hombre, núm. 68, Universidad Veracruzana, México, pp. 38-44.

Dow, James W., 1974, Santos y supervivencias: funciones de la religión en una comunidad otomí, Instituto $\mathrm{Na}$ cional Indigenista, México.

Galarza, Joaquín, 1992, Códices Testerianos. Catecismos Indígenas. El Pater Noster, Tava, México.

Galinier, Jacques, 1990, La mitad del mundo. Cuerpo y cosmos en los rituales otomíes, Universidad Nacional Autónoma de México, Instituto NacionaI Indigenista, Centro de Estudios Mexicanos y Centroamericanos, México.

— 2009, El espejo otomí. De la etnografía a la antropología psicoanalítica, Instituto Nacional de Antropología e Historia, Centro de Estudios Mexicanos y Centroamericanos, Comisión Nacional para el Desarrollo de los Pueblos Indígenas, México.

García Téllez, Alfonso Margarito, s/f, Libro de curación de antigua, ceremonia religiosa contra la brujería, Alfonso Margarito García Téllez ed., San Pablito, Pahuatlán.

__ 1978, Tratamiento de una ofrenda para pedir la lluvia en San Pablito Pahuatlán, Pue., Alfonso Margarito García Téllez ed., San Pablito, Pahuatlán.

Garibay Mora, Ernesto, 2005, Diccionario de demonios y conceptos afines, Editorial Lectorum, México.

Gruzinski, Serge, 1988, El poder sin límites. Cuatro respuestas indígenas a la dominación española, Instituto Nacional de Antropología e Historia, Instituto Francés de América Latina, México. 
Heiras Rodríguez, Carlos, 2007, "Elogio de la diferencia: mitología y ritual en la Huasteca Sur", en Diario de Campo. Boletín Interno de los Investigadores del Área de Antropología, núm. 92, Coordinación Nacional de Antropología, Instituto Nacional de Antropología e Historia, México, pp. 64-71.

Instituto Nacional de Estadística, Geografía e Informática (INEGI), 1987, Síntesis Geográfica Nomenclátor y Anexo Cartográfico del Estado de Puebla, Instituto Nacional de Estadística, Geografía e Informática, México.

- 2005, Conteo de Población y Vivienda 2005, en línea: <http://www.inegi.org.mx/est/contenidos/proyectos/ccpv/cpv2005/Default.aspx>.

Jakobson, Roman y Stephen Rudy, 1962, "On the Theory of Phonological Affinities between Languages", en Roman Jakobson, Selected Writings, The Hague Mouton, París, pp. 234-246.

Kramer, Heinrich y James Sprenger, 2004, Malleus Maleficarum, Ediciones Orión, Barcelona.

León Portilla, Miguel, 2003, Obras de Miguel León Portilla, Universidad Nacional Autónoma de México, El Colegio de México, México.

López Austin, Alfredo, 2001, "El núcleo duro, la cosmovisión y la tradición mesoamericana”, en Johanna Broda y Félix Báez-Jorge (coords.), Cosmovisión, ritual $e$ identidad de los pueblos indígenas de México, Fondo de Cultura Económica, Consejo Nacional para la Cultura y las Artes, México, pp. 47-65.

Lupo, Alessandro, 1995, La tierra nos escucha. La cosmología de los nahuas a través de las súplicas rituales, Consejo Nacional para la Cultura y las Artes, Instituto Nacional Indigenista, México.

Montemayor, Carlos, 2000, "La cosmovisión de los actuales grupos indígenas de México", en Desacatos. Revista de Antropología Social, núm. 5, Centro de Investigaciones y Estudios Superiores en Antropología Social, pp. 95-106.

Oliver Vega, Beatriz, 1997, Papel ceremonial entre los otomíes, Instituto Nacional de Antropología e Historia, México.

Rodríguez Villegas, Miguel, s/f, Diccionario español-otomí en línea, AULEx, en línea: <http://aulex.ohui.net/es-oto/>.

Sahagún, Bernardino de, 2000, Historia general de las cosas de la Nueva España, Consejo Nacional para la Cultura y las Artes, México.

Sandstrom, Alan y Pamela Sandstrom, 1986, Traditional Papermaking and Paper Cult Figures of Mexico, University of Oklahoma Press, Oklahoma.

Simeón, Remi, 2004, Diccionario de la lengua náhuatl o mexicana, Siglo XXI, México. 